\title{
Analysis of Broadband Records from the 28 June 1992 Big Bear Earthquake: Evidence of a Multiple-Event Source
}

\author{
by Laura E. Jones and Susan E. Hough
}

\begin{abstract}
The 28 June 1992 Big Bear earthquake occurred at 15:05:21 GMT and is considered to be an aftershock of the earlier $M_{w}=7.3$ Landers earthquake. From overall aftershock locations and long-period focal studies, rupture is generally assumed to have propagated northeast. No surface rupture was found, however, and the mainshock locations determined from both strong motion and TERRAscope data are mutually consistent and do not lie on the assumed fault plane. Further, directivity analysis of records from the TERRAscope array suggests significant short- and long-period energy propagating northwest along the presumed antithetic fault plane. This observation is supported by significant early aftershocks distributed along both the presumed rupture plane and the antithetic plane to the northwest. An empirical Green's function (eGf) approach using both the $M_{w}=5.2,28$ June 1992 14:43 GMT foreshock and the $M_{w}=5.017$ August 1992 aftershock produces consistent results and suggests that the Big Bear event comprised at least two substantial subevents. From the eGf results, we infer that the second and possibly a third subevent occurred on the presumed (northeast striking) mainshock rupture surface, but that significant moment release occurred on the antithetic northwest striking surface. We present results from line-source fault modeling of broadband displacement recordings of the Big Bear mainshock, which indicate that a two-fault event is necessary to produce the observed waveforms. The limitations imposed by the mainshock location and directivity analysis require that the initial rupture be towards the northwest, striking $320^{\circ}$. This was followed approximately $4 \mathrm{sec}$ later by bilateral rupture along a northeast-southwest fault that strikes $50^{\circ}$ east of north.
\end{abstract}

Introduction

The $M_{w}=7.3$ Landers earthquake of 11:58 GMT on 28 June 1992 was followed by tens of thousands of aftershocks (Kanamori et al., 1992; Hauksson et al., 1993; Sieh et al., 1993). The largest of these was the Big Bear earthquake that occurred three hours later and was associated with significant damage in Big Bear City. This event was assigned a $M_{w}$ of 6.2 based on preliminary surface-wave modeling $(\mathrm{H}$. K. Thio, personal comm., 1992). In this article, we obtain a total $M_{w}$ of 6.4 to 6.5 distributed over two distinct fault ruptures.

The Big Bear earthquake was considered an aftershock of the Landers earthquake because it occurred within one fault length of the mainshock (Sieh et al., 1993), yet it occurred on a separate and previously unmapped fault. Although eclipsed by the larger Landers mainshock, the Big Bear earthquake was a significant event in its own right. In addition to the considerable damage caused by the event, the lack of observed surface rupture makes the rupture process of this event more enigmatic. The Big Bear earthquake is associated with its own fore- and aftershock sequences, including several earthquakes in the $M 4$ to 5 range. Hereafter, we refer to the Big Bear event as a "mainshock." The Big Bear event was recorded on-scale by the low-gain channels at five stations of the TERRAscope array (Fig. 1).

We obtain a focal mechanism for the Big Bear mainshock using the grid-search method of Zhao and Helmberger (1993) and broadband data convolved with a long-period Press-Ewing (LP3090) instrument response; it is shown on the location map (Fig. 1), which also shows the patterns of seismicity that developed during the Landers-Big Bear sequence. The mainshock focal mechanism and depth (Table 1) agree with those obtained using long-period regional and teleseismic surface waves (Thio, personal comm., 1992). No surface rupture was observed for this event, but aftershocks generally delineate the extent of an earthquake rupture and in this case they appear to line up primarily along the NEstriking nodal plane. 


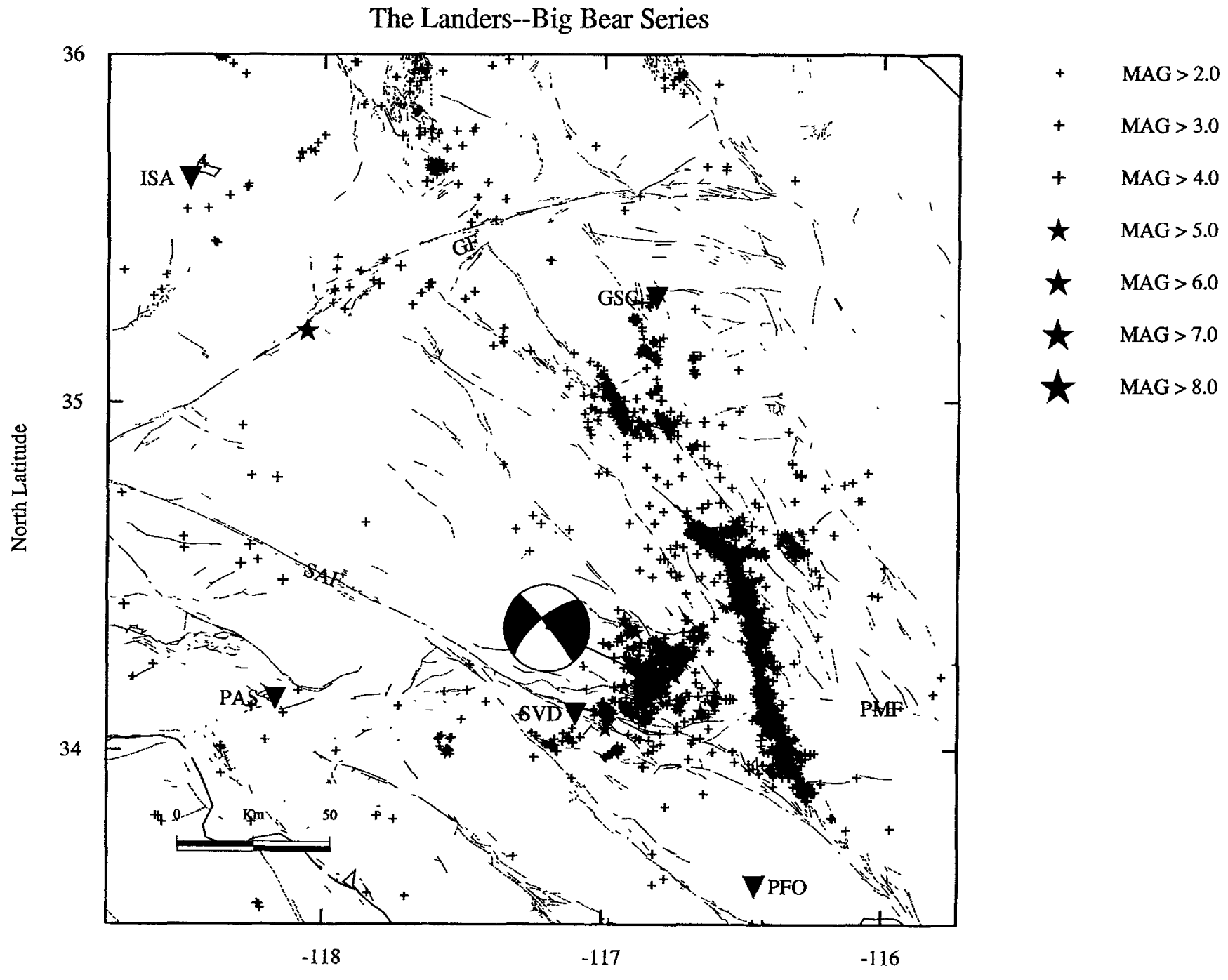

West Longitude

Figure 1. Map showing overall Landers and Big Bear seismicity. Broadband TERRAscope stations are indicated by triangles. Faults are indicated as follows: SAF (San Andreas Fault), GF (Garlock fault), and PMF (Pinto Mountain fault).

The Southern California Seismic Network (SCSN) location of the Big Bear event was presumed to be unreliable because of a $M_{b}=4$ foreshock that occurred $40 \mathrm{sec}$ before the mainshock (Hauksson et al., 1993), however, the foreshock was too small to yield appreciable amplitudes on the strong-motion recordings. The network location estimated from strong motion data of $34^{\circ} 12.36^{\prime} \mathrm{N}, 116^{\circ} 50.11^{\prime} \mathrm{W}$ yields a low rms residual of $0.15 \mathrm{sec}$ and appears to be well resolved (L. Wald, personal comm., 1992). This location is consistent with the location obtained from TERRAscope data: $34^{\circ} 12.6^{\prime} \mathrm{N}, 116^{\circ} 50.4^{\prime} \mathrm{W}$. Both locations are significantly distinct from the immediate foreshock location, $34^{\circ}$ $9.94^{\prime} \mathrm{N}, 116^{\circ} 49.38^{\prime} \mathrm{W}$, which lies roughly $5.5 \mathrm{~km}$ to the southeast of the mainshock. The Big Bear earthquake was recorded by strong-motion stations operated by the SCSN and by six broadband TERRAscope stations. In this article, we analyze data from five TERRAscope stations (GSC, ISA, PAS, PFO, SVD; see Fig. 1) to investigate the Big Bear fore-, main-, and aftershock sequence and to place limits on the rupture characteristics of the Big Bear mainshock.

\section{The Big Bear Mainshock}

To guide our subsequent more-detailed investigations, we first obtain average source parameters, including source depth, for the Big Bear mainshock using a grid-search source estimation algorithm developed by Zhao and Helmberger (1994). This algorithm selects the source mechanism that minimizes the L1 and L2 norms between the data and synthetics, using $P_{n l}$ waveforms plus whole waveforms (ideally) for all three components to reduce the effects of data-model misfit and produce a stable solution from a relatively sparse 
Table 1

Big Bear Events

\begin{tabular}{|c|c|c|c|c|c|c|c|}
\hline \multirow[b]{2}{*}{ Date } & \multirow[b]{2}{*}{$M_{w}$} & \multirow[b]{2}{*}{ Strike } & \multirow[b]{2}{*}{ Dip } & \multirow[b]{2}{*}{ Rake } & \multicolumn{3}{|c|}{ Location } \\
\hline & & & & & $\begin{array}{l}\text { Depth } \\
(\mathrm{km})\end{array}$ & $\begin{array}{l}\text { Latitude } \\
\left({ }^{\circ} \mathrm{N}\right)\end{array}$ & $\begin{array}{l}\text { Longitude } \\
\text { ("W) }\end{array}$ \\
\hline 1. 9206281443 & 5.2 & 210 & 86 & 330 & 14 & 34.16 & 116.85 \\
\hline 2. Mainshock & 6.5 & 320 & 86 & 200 & $11-14$ & 34.21 & 116.83 \\
\hline 3. 9206281701 & 4.8 & 118 & 83 & 145 & 14 & 34.18 & 116.92 \\
\hline 4. 9206281748 & 4.3 & 324 & 90 & 200 & 8 & 34.22 & 116.75 \\
\hline 5. 9206291441 & 4.4 & 113 & 85 & 150 & 7 & 34.12 & 116.99 \\
\hline 6. 9207012053 & 4.0 & 343 & 90 & 214 & 6 & 34.29 & 116.72 \\
\hline 7. 9207030415 & 3.9 & 230 & 80 & 150 & 16 & 34.18 & 116.78 \\
\hline 8. 9207090143 & 5.3 & 246 & 46 & 102 & 2 & 34.24 & 116.84 \\
\hline 9. 9208172041 & 4.8 & 285 & 65 & 150 & 15 & 34.18 & 116.87 \\
\hline 10. 9208180946 & 4.0 & 268 & 52 & 118 & 11 & 34.18 & 116.88 \\
\hline 11. 9208241351 & 4.0 & 330 & 75 & 178 & 8 & 34.28 & 116.78 \\
\hline 12. 9211271600 & 5.2 & 118 & 70 & 176 & 5 & 34.34 & 116.88 \\
\hline 13. 9212040208 & 5.1 & 126 & 43 & 117 & 7 & 34.35 & 116.95 \\
\hline 14. 9212040525 & 4.3 & 106 & 72 & 140 & 5 & 34.37 & 116.90 \\
\hline 15. 9212041259 & 4.2 & 136 & 72 & 184 & 8 & 34.35 & 116.92 \\
\hline
\end{tabular}

data set. In this case, however, the broadband $P_{n l}$ waveforms were too complex to be usable; attempts to estimate the depth of rupture initiation using depth phases in the $P_{n l}$ waveforms were not successful. However, an "average" depth was therefore obtained, based primarily on surface wave to $P_{n l}$ amplitude ratios, using whole waveforms from TERRAscope stations Goldstone (GSC), Isabella (ISA), Pasadena (PAS) and Pinon Flats (PFO). (Seven Oaks Dam (SVD) was too proximate to the source to use in this source-estimation scheme.)

We cycled through source depths $(5,8,11,14$, and 17 $\mathrm{km}$ ) to obtain an average depth for the event (Fig. 2). Source parameters for the five depths are consistent within $10^{\circ}$ (Table 2), and depths of 11 and $17 \mathrm{~km}$ provide minimum error solutions for the broadband waveforms, followed closely by a depth of $14 \mathrm{~km}$. Note that for every station, the modeled duration of the tangential component underpredicts that of the data and that several peaks observed on the mainshock data for this component are not (and could not be) matched at stations GSC and PAS. Similar mismatches are observed for the radial and vertical components. Ratios of $P_{n l}$ to surface wave amplitude clearly require a source depth of at least $11 \mathrm{~km}$. For broadband data convolved with a LP3090 instrument, a depth of $17 \mathrm{~km}$ produces the lowest error solution. The source-time function was fixed by cycling through simple triangles ( 0.4 to $4 \mathrm{sec}$ duration) and selecting the one that minimized error, in this case, a $1.0 \mathrm{sec}$ triangle, though records at PFO clearly require a longer time-function. A solution using records from PFO alone produced a sourcemechanism consistent with the four-station solution (Table 2) but required a $3.5 \mathrm{sec}$ triangle, suggesting rupture directivity away from station PFO. Given the modeled source duration of about $1 \mathrm{sec}$ and a moment (averaged for depths of 11 and $14 \mathrm{~km}$; see Table 2) of $2.0 \times 10^{25}$ dyne-cm, we estimate a stress-drop of about $3.62 \mathrm{Kbars}$ assuming a cir- cular fault model. Not only is the moment obtained assuming a single source too low, but the stress drop under this assumption is unreasonably high. This result, and the complexity of the recorded waveforms, suggest that the mainshock may be composed of separate smaller subevents, initiating several seconds after each other.

\section{The Big Bear Sequence}

Three significant $(M>4)$ foreshocks to the Big Bear mainshock and more than 550 aftershocks $(M>1.9)$ were recorded between 28 June 1992 and 31 December 1992. The Big Bear sequence appears to have occurred entirely within the San Bernardino Mountains block, which is bounded on the north by the North Frontal fault zone (Meisling and Weldon, 1989) and on the south by the Mill Creek fault and the San Bernardino segment of the San Andreas fault (Matti et $a l ., 1992)$. Seismicity appears to shallow to the north and to the south, suggesting that these bounding faults may define a spatial boundary for the deformation associated with the Big Bear sequence (Hauksson, 1993).

We determine fault-plane solutions for twelve significant $\left(M_{w}>4\right)$ aftershocks, plus the 14:43 GMT $M_{w}=5.3$ foreshock and the mainshock using a grid-search algorithm developed by Zhao and Helmberger (1994). The selection of earthquakes examined includes every event above magnitude 3.9 for which coherent, high signal-to-noise TERRAscope data are available (Fig. 3a, Table 1). The sequence is dominated by relatively deep (12 to $17 \mathrm{~km}$ ) to intermediate ( 7 to $11 \mathrm{~km}$ ) depth northwest-striking right lateral and northeast-striking left lateral strike-slip events on trends parallel to both planes of the mainshock source mechanism. We infer that the left lateral earthquakes lie along or form trends parallel to the broad northeast trending swath of seismicity seen in Figure 1, while right lateral and thrust 

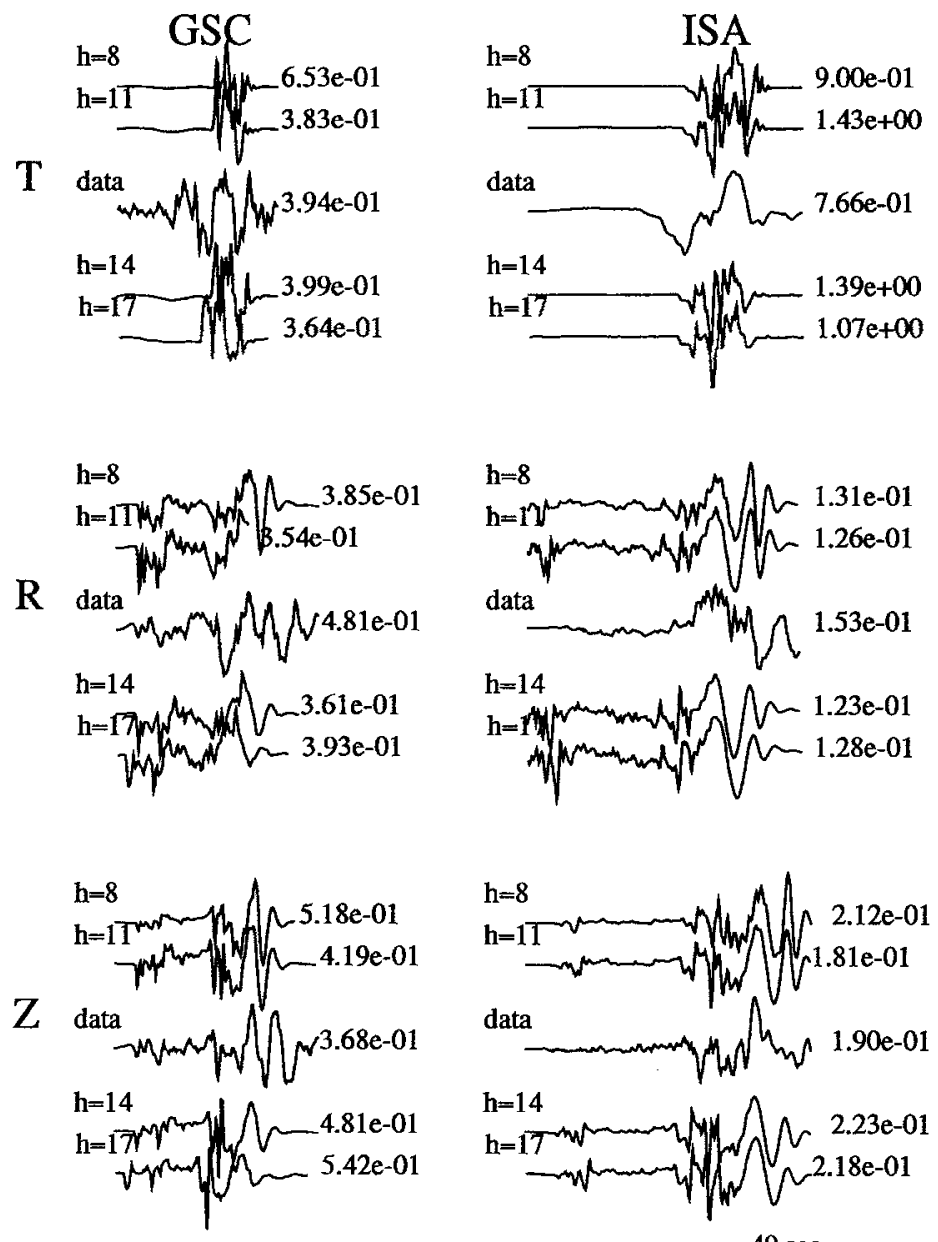
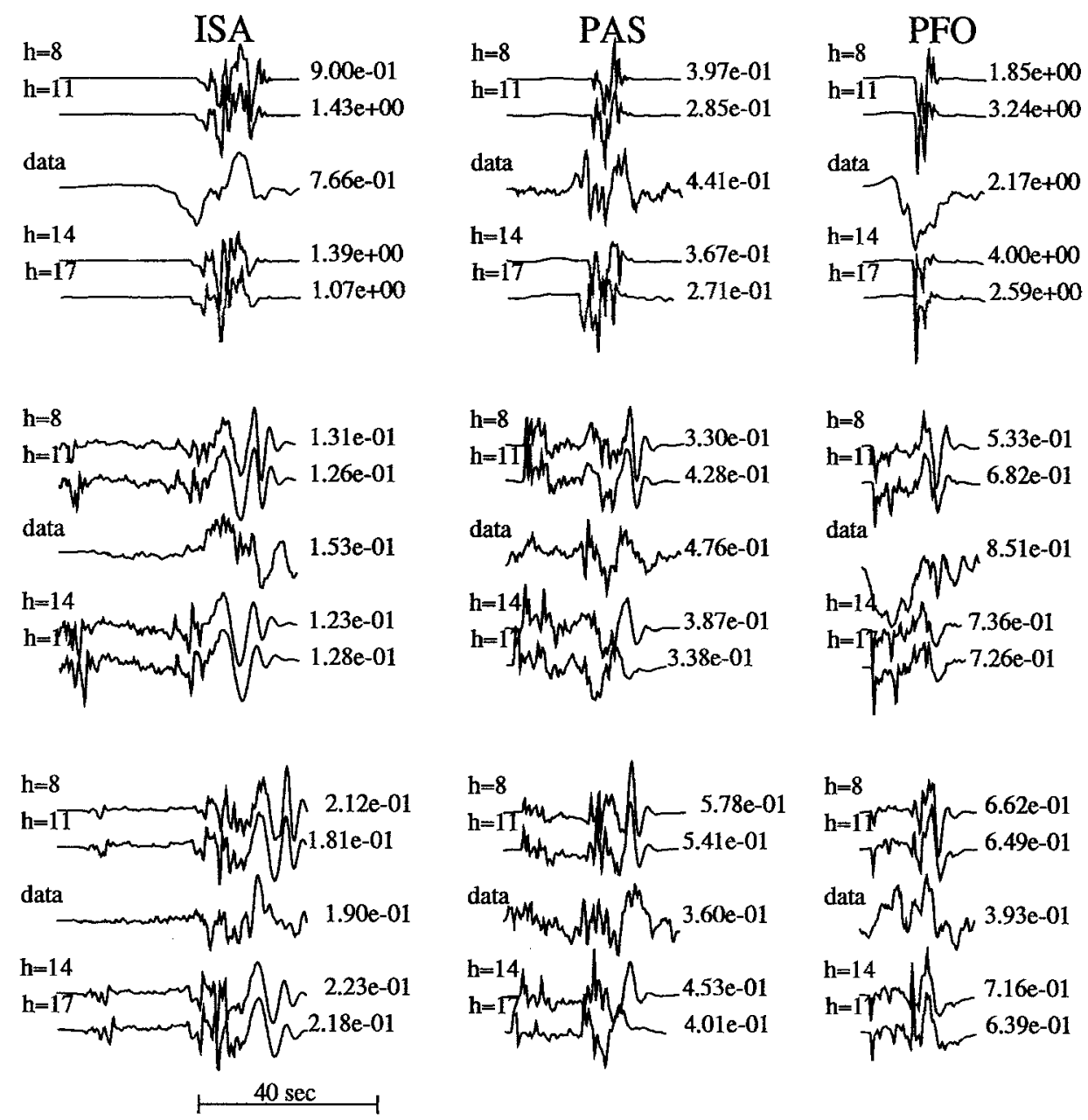

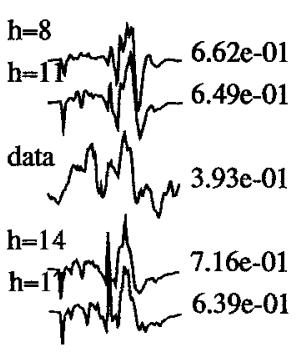

Figure 2. Point-source modeling results for the Big Bear mainshock for sourcedepths of $8,11,14$, and $17 \mathrm{~km}$. The source orientations (listed by depth in Table 2) are determined using a grid-search algorithm developed by Zhao and Helmberger (1994). The best-fit source-time function (assuming one source) is a $1.0 \mathrm{sec}$ triangle, though records at PFO clearly require a longer time function. Synthetics for the source estimation are computed using the reflectivity method and the Standard Southern California model (Hadley and Kanamori, 1977).

Table 2

Point Source Results

\begin{tabular}{lrcccc}
\hline \multicolumn{1}{c}{ Source } & $\begin{array}{c}\text { Depth } \\
(\mathrm{km})\end{array}$ & $\begin{array}{c}\text { Moment } \\
\text { (dyne-cm) }\end{array}$ & Strike & Dip & Rake \\
\hline This study & 5 & $7.5 \times 10^{24}$ & 223 & 62 & 353 \\
This study & 8 & $1.4 \times 10^{25}$ & 216 & 71 & 347 \\
This study & 11 & $2.1 \times 10^{25}$ & 220 & 85 & 348 \\
This study & 14 & $1.9 \times 10^{25}$ & 216 & 82 & 344 \\
This study & 17 & $2.1 \times 10^{25}$ & 217 & 88 & 337 \\
Thio (1992) & 13 & $2.8 \times 10^{25}$ & 217 & 86 & 343 \\
\hline
\end{tabular}

events tend to lie along northwest trends and along the northern and southwestern ends of the aftershock trends. Two shallow thrust events occurred (4 December 1992) along the frontal fault that bounds the northern extent of the aftershock sequence, and two oblique-slip to thrust events (17 and 18
August 1992) were recorded at the southwestern ends of the aftershock trends. Focusing on aftershocks that occurred within the first $24 \mathrm{hr}$ of the Big Bear mainshock (Fig. 3b), an upside-down T-shaped pattern is evident, with events both along the presumed NE-striking rupture plane and the NW-striking antithetic plane.

\section{Analysis}

\section{Directivity Analysis}

The location of the Big Bear mainshock hypocenter being north and west of the observed long-term NE-trending aftershock trend, yet parallel to northwest-trending short-term aftershock activity (Figs. $3 a$ and $3 b$ ), suggests initial rupture to the northwest. To investigate rupture directivity, we compare the short-and long-period amplitudes of the Big Bear 
Big Bear Series, $M>2.0$.

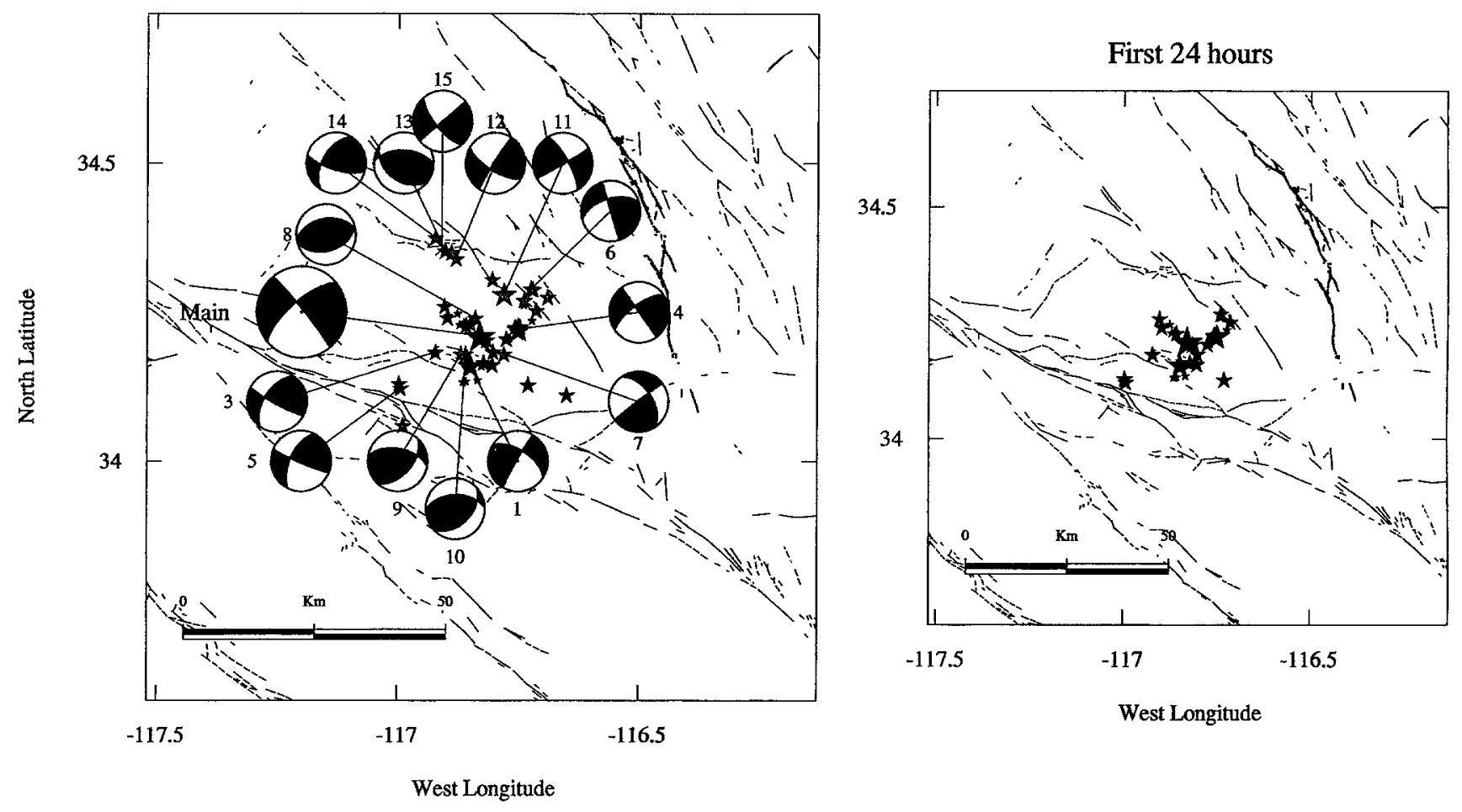

Figure 3. (a) Map showing the location of the Big Bear earthquake (large star) and the location of other $M>1.9$ aftershocks in the sequence, through 31 December 1992 (smaller stars). Filled symbols indicate fore- and aftershocks occurring within the first day of the mainshock; open symbols indicate later events. Events with focal spheres are numbered in the order of occurrence and listed in the same order on Table 1. The focal mechanisms are determined by a grid-search method (Zhao and Helmberger, 1994). Landers rupture is shown with heavy line. (b) Map showing aftershocks that occurred within the first $24 \mathrm{hr}$ of the mainshock. Mainshock is shown as large star.

event with amplitudes of smaller events in the sequence. As discussed by Helmberger et al. (1992), this type of comparison can be used to indicate the rupture direction. Analogous to the empirical Green's function method, this amplitude analysis isolates source properties of the mainshock by assuming path effects and (in this case) radiation pattern are similar between the mainshock and the nearby smaller event.

For this study we have used the the 28 June 1992 14:43 foreshock, the 28 June 1992 17:48 aftershock, the 17 August 1992 M 4.8 aftershock, and the 24 August 1992 aftershock as "master" or reference events. Again, because ISA and PFO are nodal or near nodal for $P$ energy and are at $S H$ maxima, we examine the tangential components of displacement for these stations. Similarly, since PAS and GSC are at or near SH minima, we examine their vertical components of motion. The broadband displacement records (integrated from acceleration in the case of the mainshock and from velocity in the case of the master events) have been convolved with a short-period Wood-Anderson instrument response, which has a peak response at a dominant frequency of about $1 \mathrm{~Hz}$, and the ratios of the peak short-period amplitudes for the tangential component (all 4 stations) are shown plotted against station-event azimuth in Figure 4a. The average sta- tion-event azimuth is indicated above the top curve (see station names), and all four curves are normalized such that the amplitude at GSC is 100 . It is immediately evident that shortperiod amplitudes are highest in the direction of ISA and taper off to minima about $180^{\circ}$ azimuth from ISA, i.e., in the approximate direction of PFO. The solid, thick curve represents a simple theoretical computation for the doppler-shift effects on amplitude, assuming rupture toward station ISA and a rupture velocity of 0.7 times the assumed crustal shear wave velocity $(3.0 \mathrm{~km} / \mathrm{s}$ ) (Aki and Richards, 1980). The same comparison for the vertical components is shown in Figure 4b. Again, the amplitude ratios at ISA are consistently higher, and the ratios at stations PAS and GSC behave more as we might expect them to from the theoretical computation (unbroken line). Similar short-period analysis was performed for the 28 June 1992 14:43 foreshock, using the 28 June 1992 17:48 aftershock, the 17 August 1992 aftershock and the 24 August 1992 aftershock as "master events" (Fig. 4 , panel c). In this case, it is evident that energy release was primarily to the north, in the direction of station GSC.

Long-period directivity studies were also performed, in which the broadband records were convolved with an LP3090 instrument response, which has a peak response at 


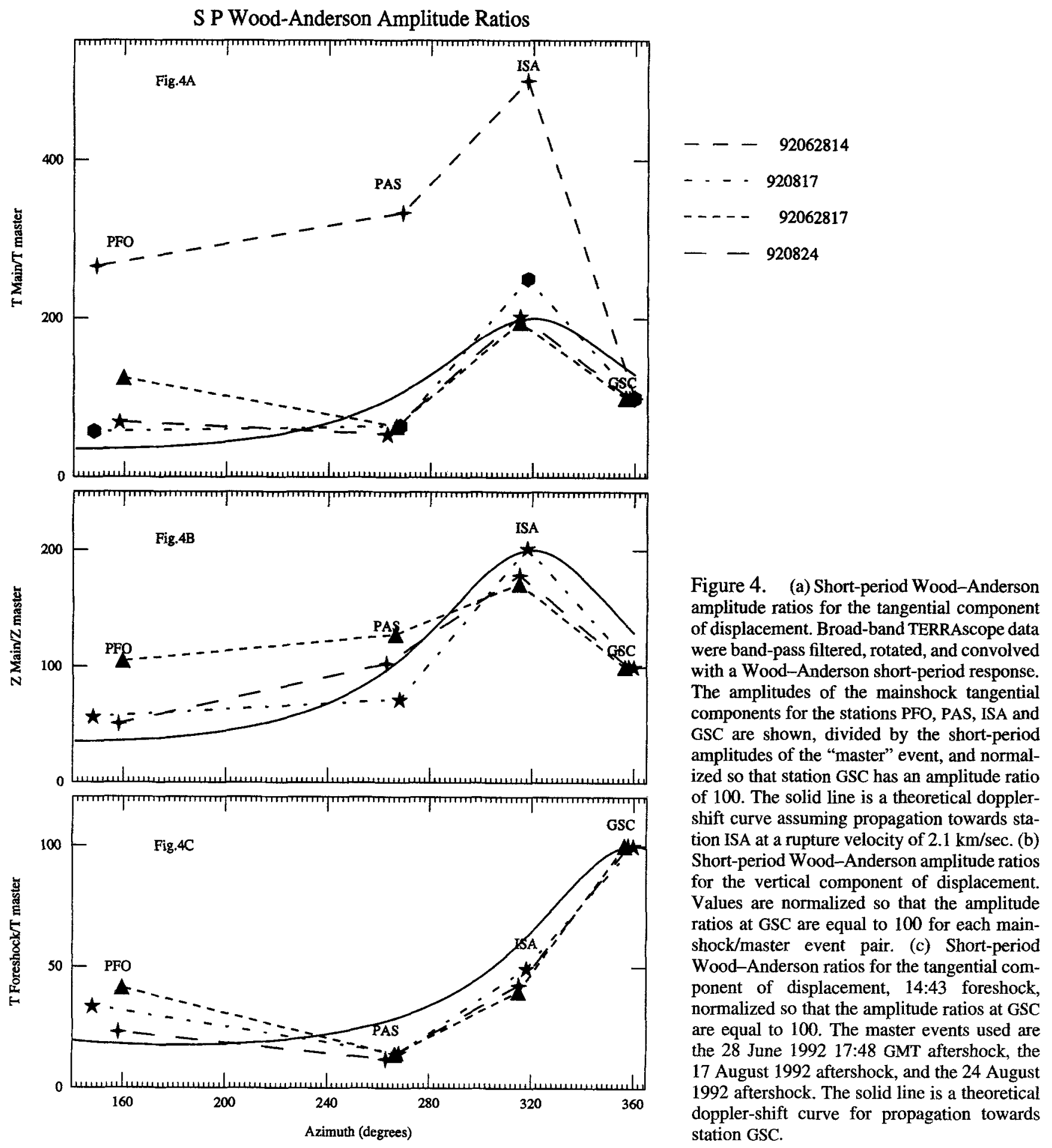

about $30 \mathrm{sec}$, and the amplitude ratios examined as described above. In this case, the curves flattened out at the lower frequencies, retaining only amplitude effects from small radiation pattern differences (between mainshock and master event) at nodal stations.

\section{Empirical Green's Function Analysis}

To investigate the apparent complexity of the mainshock, particularly the possibility that it is composed of dis- tinct subevents, we first apply an empirical Green's function (eGf) method. Numerous studies have demonstrated that the eGf method, whereby complex path effects are deconvolved from an earthquake recording using a nearby smaller earthquake, can provide accurate estimates of source parameters under certain circumstances (Bakun and Bufe, 1975; Mori and Hartzell, 1990; Ammon et al., 1992). Empirical Green's functions can be used either with inverse methods to decon- 
volve source properties (e.g., Mueller, 1985; Mori and Hartzell, 1990) or in forward modeling efforts to "construct" a large earthquake from one or more smaller events (e.g., Wennerberg, 1993). Ideally, an eGf should be at the same location and have the same source mechanism as the event that is being investigated to insure that both events have similar source and propagation characteristics. However, with longer period data, the method has been applied successfully using eGf-mainshock pairs that are separated by as much as a few kilometers (Ammon et al., 1992).

Applying an eGf method to the Big Bear earthquake is complicated by the fact that no well-recorded Big Bear aftershock is an ideal empirical Green's function. Furthermore, if the mainshock consisted of two separate subevents at different depths, no single ideal eGf could exist. The foreshock is approximately $7 \mathrm{~km}$ southwest of the mainshock but has a similar depth of $14 \mathrm{~km}$ (from grid-search solution), a similar mechanism and waveforms (Fig. 3a and Table 1). Likewise, two aftershocks have similar mechanisms, and locations within 6 to $9 \mathrm{~km}$ of the mainshock, (roughly $8.8 \mathrm{~km}$ east and $6 \mathrm{~km}$ southwest of the mainshock and at depths of 8 and $15 \mathrm{~km}$, respectively). For the Big Bear event, we select as an eGf the $M 4.8$ aftershock, which occurred at $20: 41$ GMT on 17 August 1992. Our earlier work featured the $M_{w}$ $=5.2$ foreshock that occurred at 14:43 GMT on 28 June 1992 as eGf (Jones et al., 1993).

Empirical Green's function deconvolutions for source time functions are unstable for myriad reasons (Mori and Hartzell, 1990). The deconvolution procedure involves computation of a spectral ratio and then an inverse Fourier transform to the time domain. The computational uncertainties associated with these procedures are well documented in other studies. In this study, we adopt a forward modeling approach whereby recordings of the eGf are convolved with source time functions that contain one or more pulses. We prefer this approach for the Big Bear earthquake because it allows a direct investigation of the number of subevents required to fit the data (deconvolutions are often plagued by side lobes that can be difficult to interpret). Fundamentally, however, the two methods are conceptually consistent; they differ only in the choice of how to deal with computational uncertainty. The pulses used for convolution with the empirical Green's functions are computed using a simple exponential function designed to scale the frequency content of the source and insure that the low-frequency energy of the eGf is scaled up to higher magnitudes. This is conceptually analogous to the frequency-domain method presented by Wennerberg (1990). The mainshock observations used in this study are accelerograms from four stations (GSC, ISA, PAS, PFO) in the TERRAscope array. Instrument gain was removed from these records; they were doubly integrated to obtain displacement, bandpass filtered from 0.02 to $7 \mathrm{~Hz}$ using a zero-phase, second-order Butterworth filter to preserve the broadband nature of the record, and then rotated. The aftershock records used as empirical Green's functions were very broad band (VBB) velocity records from the
TERRAscope array. They were processed similarly: instrument gain removed, integrated once to obtain displacement, bandpass filtered from 0.02 to $7 \mathrm{~Hz}$, and rotated.

Although numerous aftershocks and a foreshock to the Big Bear earthquake were satisfactorily modeled with a point source and a standard earth structure (Jones and Helmberger, 1993), we have shown that the observed mainshock waveform complexity cannot be fit with a simple, singlepulse source-time function (Fig. 2). A single-pulse sourcetime function of duration appropriate to an $M=6$ to 6.5 earthquake ( $5 \mathrm{sec}$ ) is also tested using the eGf approach (Fig. 5a) and fails to approximate either the frequency content or waveform shape of mainshock records. As the previous fixed-pulse models clearly fail, we test a simple, variable width single-pulse time history using the eGf approach (Fig. $5 \mathrm{~b})$. Source-time function durations are assumed to be $1 \mathrm{sec}$ for stations ISA and GSC, $1.2 \mathrm{sec}$ at PAS, and $3.5 \mathrm{sec}$ at PFO, based on earlier point-source modeling (Fig. 2). In each case, even allowing for variation in pulse width between stations, the single-pulse model fails to match significant arrivals on the mainshock waveforms (Fig. 5b).

Substantially better results are obtained with the addition of a second pulse (Figs. 6a and 6b). Records at stations PAS and GSC require source-time functions composed of two pulses (Fig. 6b). For TERRAscope stations PFO and ISA, a third subevent is also suggested (Fig. 6b). Consistent results were obtained by Jones et al. (1993) using the 14:43 GMT foreshock as eGf. Although the modeling results are not perfect, they are successful in matching many of the more salient features of the observations and represent a clear improvement over the single-pulse model results shown in Figures 2 and 5.

The pulse widths in the inferred source-time functions (Fig. 6b) cannot be interpreted in terms of source-time function durations because they indicate the pulse width relative to that of the empirical Green's function (note that amplitudes are relative to the amplitude ratios of the mainshock and empirical Green's function at each station). For the 17 August 1992 aftershock (Figs. 6a and 6b) with a moment of $2.93 \times 10^{23}$, we obtain a moment of $5.34 \times 10^{25}$, equivalent to a moment magnitude of $M_{w}=6.42$. Given the effective source-time functions we derived from the foreshock (Jones et al., 1993) and the moment of the foreshock, a moment of $5.3 \times 10^{25}$ is obtained for the Big Bear mainshock. This is equivalent to a moment magnitude of $M_{w}=6.48$.

Assuming that the two pulses at stations GSC and PAS correspond to the first two pulses at stations ISA and PFO, we can use the inferred subevent spacings to solve for a relative location of the second subevent. Assuming further that the first subevent occurs at the SCSN-determined epicenter and that the subevent spacing is small compared to the event-station spacings, a parameter-search method is used to infer the subevent temporal and spatial spacing. An optimal solution yields a second subevent occurring $3.7 \mathrm{sec}$ after the first, roughly $3.2 \mathrm{~km}$ and $15^{\circ}$ east of south from the first subevent. Thus, the inferred subevent spacing toward 
920817

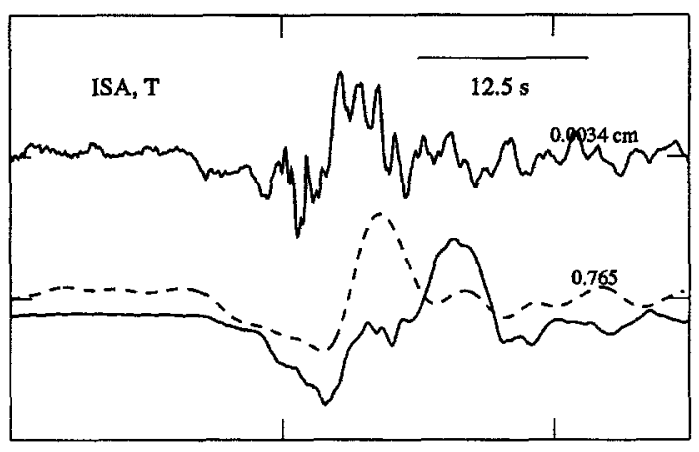

PFO, T
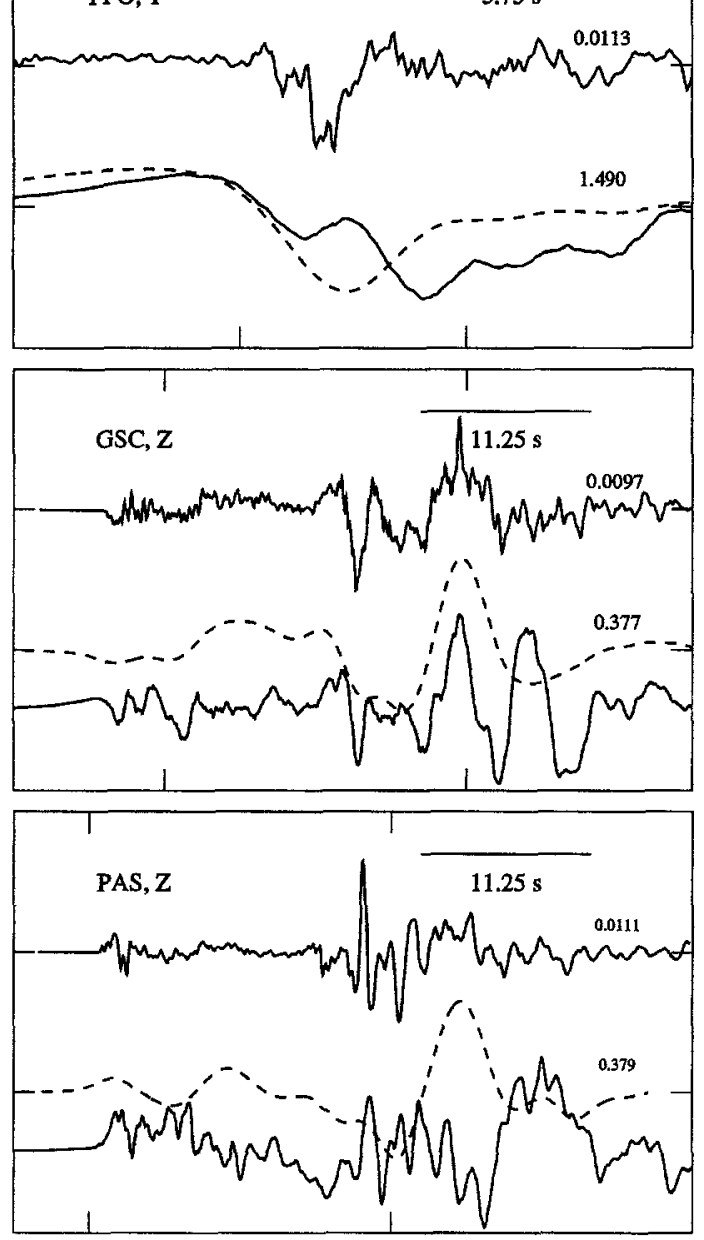

(a)
920817

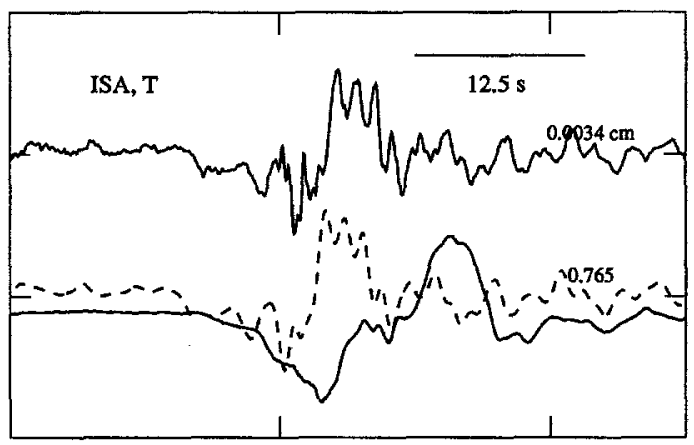

PFO, T

$3.75 \mathrm{~s}$
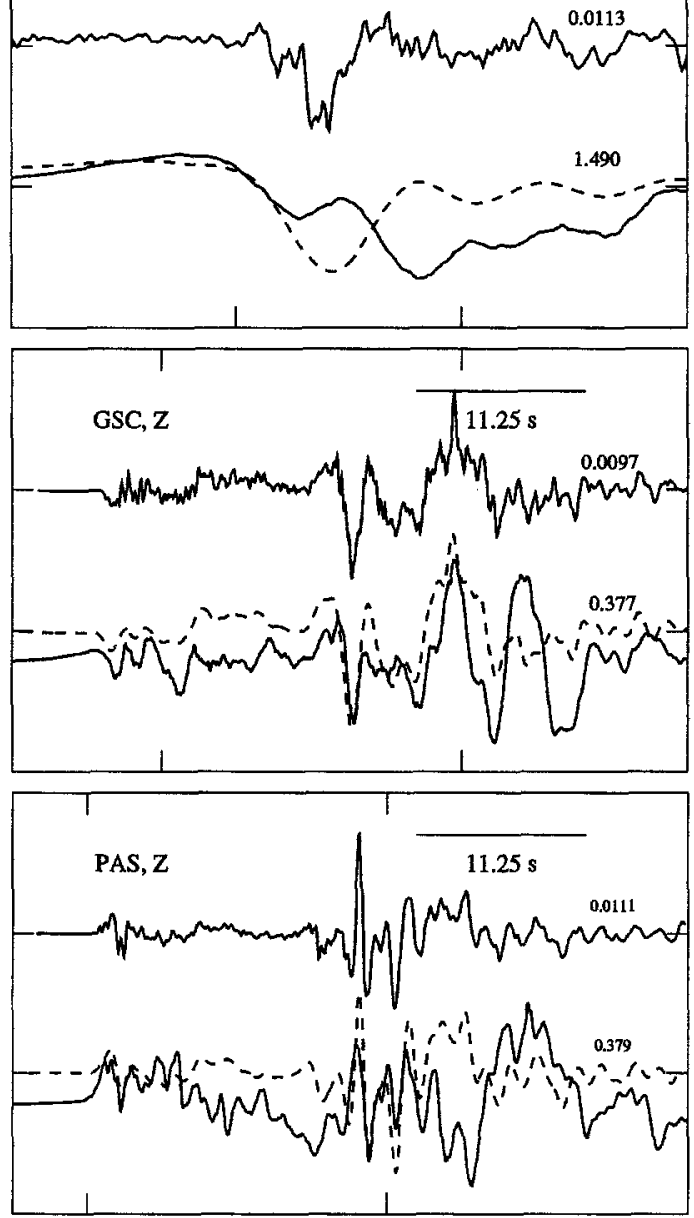

(b)

Figure 5. (a) The four panels show results for 17 August 1992 aftershock as eGf, assuming a simple, single-pulse model. The pulse duration is $5 \mathrm{sec}$, which is roughly what might be expected for an earthquake the size of the Big Bear mainshock. For stations ISA and PFO, on or near $S H$ maxima, results for the tangential component of motion are shown. For stations GSC and PAS, on or near $P$-wave maxima, results for the vertical component of motion are shown. (b) The four panels show results assuming a simple variable-width single-pulse model. The source-time functions at stations GSC and ISA are $1 \mathrm{sec}$ pulses, as observed in earlier point source modeling (Fig. 2); source duration at PAS is $1.2 \mathrm{sec}$ and that at station PFO is $3.5 \mathrm{sec}$ (from single-station point-source solutions using data from PAS and PFO, respectively). In each panel, the top trace is the raw eGf data, the dashed trace is the convolution of the eGf with the source-time function, and the bottom solid trace is mainshock data. Prior to convolution, the source-time functions are scaled to unit area. 
920817
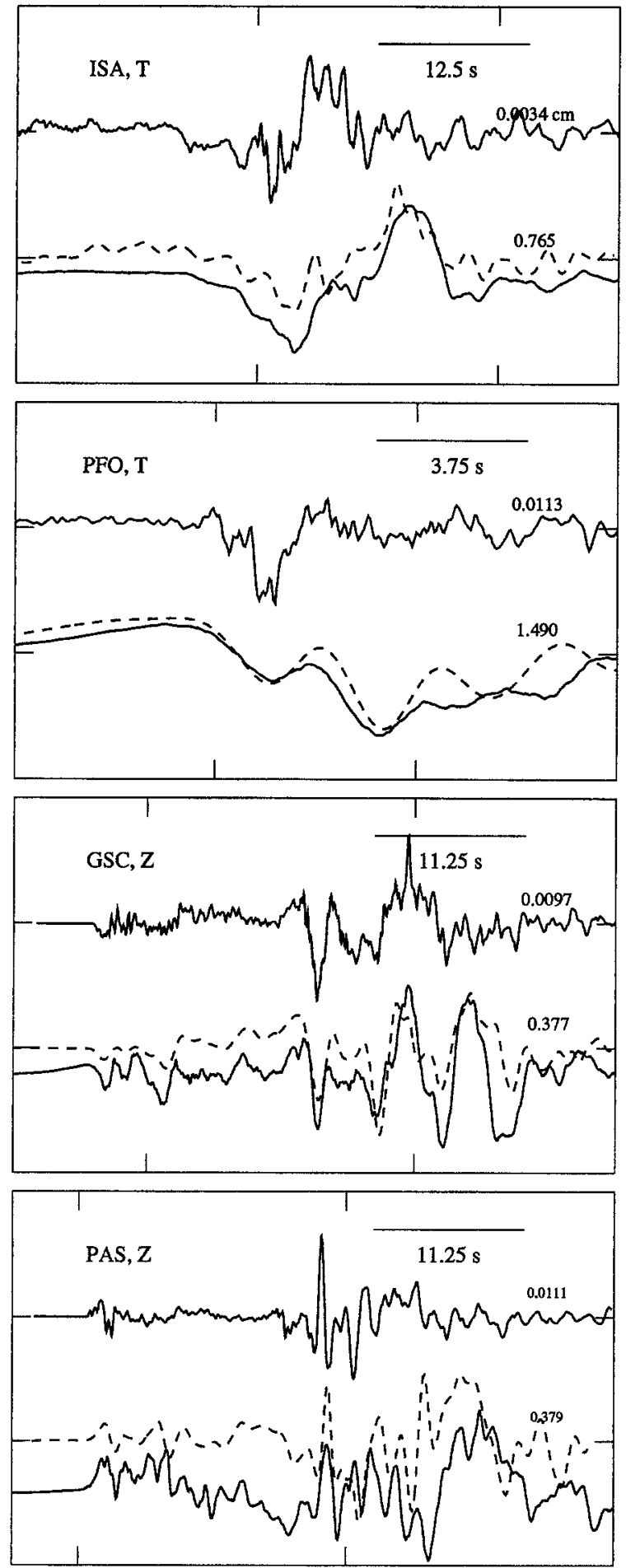

(a)

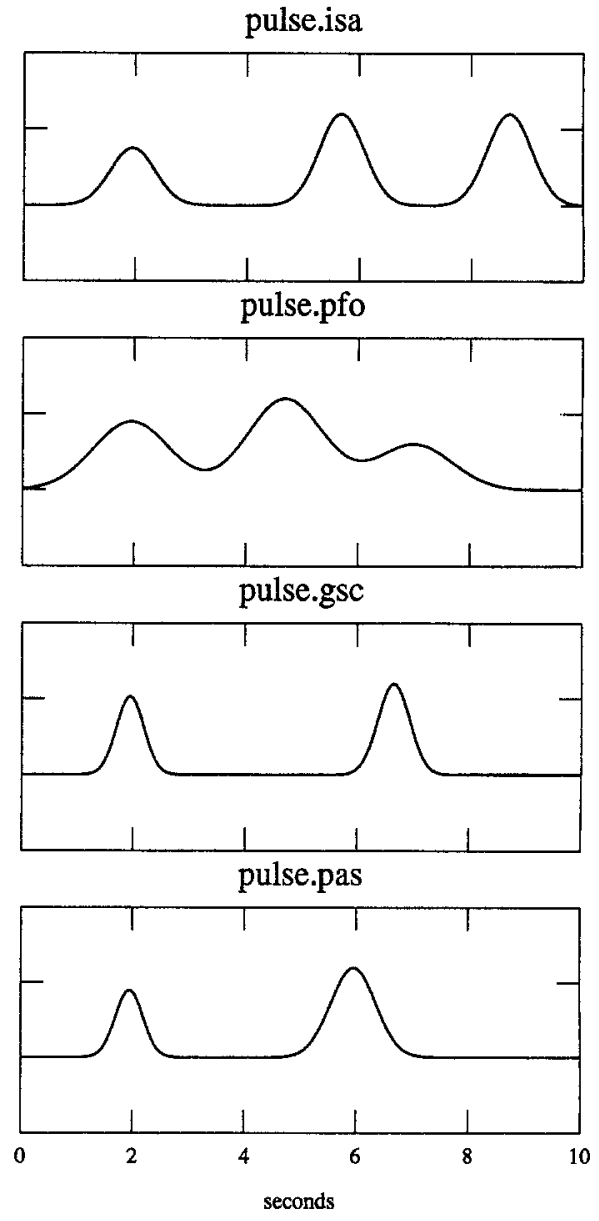

(b)

Figure 6. (a) The four panels show results for the choice of 17 August 1992 aftershock as eGf. For stations ISA and PFO, on or near SH maxima, results for the tangential component of motion are shown. For stations GSC and PAS, on or near $P$-wave maxima, results for the vertical component of motion are shown. The top trace is the raw eGf data, the dashed trace is the convolution of the eGf with the source-time function, and the bottom solid trace is mainshock data. (b) Preferred source-time functions for the choice of the 17 August 1992 aftershock as eGf. The source-time functions are scaled to unit area prior to convolution. 
PFO is $3.7 \mathrm{sec}$ minus the travel time projected on the azimuth towards PFO, while the inferred spacing toward ISA is roughly $3.7 \mathrm{sec}$ plus the same amount. The location of the third postulated subevent cannot be determined from our results.

\section{Line-Source Fault Models}

Motivated by results from our empirical Green's function study, which suggest a Big Bear mainshock composed of at least two subevents, coupled with directivity results suggesting substantial rupture to the northwest, we attempt to place further limits on the Big Bear rupture characteristics by performing a line-source fault inversion study.

A damped, nonnegative, least-squares inversion procedure (Lawson and Hanson, 1974) is used to obtain the subfault weighting values that give the best fit to the mainshock velocity and displacement waveforms. Additional limits are imposed by the choice of empirical Green's function used in the summation and inversion. As with the earlier pointsource study, the eGf must be chosen carefully so that source depth, source mechanism, and source-station distance are appropriate for each source-station pair used in the inversion. To solve for the weighting amplitudes on each subfault, given the selected eGf seismograms and the mainshock observations, we solve the following overdetermined system of linear equations: $\mathbf{A x}=\mathbf{b}$, where $\mathbf{A}$ is the matrix of subfault synthetics (in this case, eGfs), $\mathbf{x}$ is the solution vector, consisting of subfault weights, and $\mathbf{b}$ is the data (observed) vector. We invert explicitly for subfault weightings. Other parameters must be specified, i.e., the smoothing weights for each inversion, rupture velocities, weighting for each trace, lag time between fault ruptures (for rupture geometries including more than one fault), and fault geometry. Numerous inversions were performed in this study, and the results presented below represent our best solutions for each given choice of eGf and contain features consistent across all eGfs. Inversions were also run using theoretical Green's functions similar to those used in the point source modeling shown in Figure 2, producing results consistent with those obtained from the two eGfs but with a substantially higher leastsquares misfit.

Two aftershocks (28 June 1992 17:48 and 17 August 1992 20:41 GMT) were selected as empirical Green's functions for this procedure. Mainshock data and the data used as empirical Green's functions were processed as described earlier in the section on eGf summation. Both the mainshock and eGf data were subsequently low-pass filtered with a corner at $0.5 \mathrm{~Hz}$. The 14:43 foreshock is not used here because of its own demonstrated directivity. Again, we use the vertical records at PAS and GSC and add the radial, as well. For ISA and PFO, we use all three components. Nodal or nearnodal components of motion at each station were given lower weightings in the inversion. Waveforms from station SVD (at an epicentral distance of $27.4 \mathrm{~km}$ ) were included when available, as we felt it was important that the solution provide good fits for a station so close to the source. Moment was obtained, in this case and those that follow, by summing the weighting functions at each subfault and multiplying this sum by the moment of the appropriate eGf (Table 3).

We use four initial single-fault models for the Big Bear earthquake, each consisting of a $16-\mathrm{km}$-long linear fault composed of $161-\mathrm{km}$-long blocks, with a point source in the middle of each block. Fault lengths were chosen upon examination of the spatial distribution of aftershocks toward the northwest and toward the northeast. Based on directivity results, two of the models consisted of faults with northwestern strikes of $320^{\circ}$. In one case, rupture was specified to proceed unilaterally from the southeastern end of the fault to the northwestern end, at a rupture velocity of $V_{r}=2.7$ $\mathrm{km} / \mathrm{sec}$. Rupture velocities of $1.7,2.3,3.0,3.3$, and 3.7 were also tested, but the best results were obtained assuming $V_{r}$ $=2.7 \mathrm{~km} / \mathrm{sec}$. The other case featured bilateral (NW-SE) rupture at the same rupture velocity on a northwest-striking fault. To force the inversion to simulate the effect of separate, discrete subevents, we apply minimal smoothing between subfaults.

We also test two models that feature single linear 16$\mathrm{km}$ faults with a $50^{\circ}$ north-easterly strike. In these cases, rupture proceeds unilaterally from the southwestern end of the fault to the northeastern in one case and bilaterally from the epicenter in the other. Other rupture scenarios (that is, rupture beginning at the northwest end of the northweststriking fault or at the northeast end of the northeast-striking fault) are inconsistent with mainshock location and aftershock distribution.

Both unilaterally and bilaterally rupturing single-fault parameterizations failed to produce reasonable solutions, even after the fault lengths were increased so subevents could distribute themselves spatially and thus temporally as far apart as possible. Of the models run, quantified leastsquares misfit analysis indicates that, overall, weighted waveform fits provided by the NE-striking unilaterally rupturing fault are about $9 \%$ better than those provided both by the NW-striking unilaterally rupturing fault and the NEstriking bilaterally rupturing fault. However, visual waveform comparisons indicate that significant phases are not matched by the results from any of these models. Figure 7 shows results from one such single-fault model, a single bilaterally rupturing fault striking to the northeast $\left(\mathrm{N} 50^{\circ} \mathrm{E}\right)$, assuming a rupture velocity of $V_{r}=2.7 \mathrm{~km} / \mathrm{sec}$. This fault model is suggested by the mainshock source location with respect to aftershock distribution along a NE-SW trend (Fig. 3b). For this inversion, the 28 June 1992 17:48 GMT aftershock was used as an eGf. Important characteristics of several waveforms are not well modeled, including the prolonged duration of ISA (tangential component).

As we could not obtain required temporal subevent spacings from one fault without increasing its length beyond that suggested by extent of seismicity, we experimented with a number of two-fault models, using both NW and NE-striking faults. The geometry and orientation of the two faults is 
Table 3

Summary of Line Source Results

\begin{tabular}{cccccc}
\hline $\begin{array}{c}\text { eGf Date } \\
\text { (yymmddhhmm [GMT]) }\end{array}$ & $\begin{array}{c}\text { eGf } M_{w} \\
\text { (dyne-cm) }\end{array}$ & $\begin{array}{c}\text { Mainshock } M_{w} \\
\text { (dyne-cm) }\end{array}$ & $\begin{array}{c}\text { NW Fault } \\
\text { (dyne-cm) }\end{array}$ & $\begin{array}{c}\text { NE Fault } \\
\text { (dyne-cm) }\end{array}$ & $\begin{array}{c}T_{\text {he }} \\
\text { (sec) }\end{array}$ \\
\hline 9206281748 & $5.17 \times 10^{22}$ & $5.86 \times 10^{25}$ & $2.61 \times 10^{25}$ & $3.25 \times 10^{25}$ & $3.75-4.00$ \\
9208172041 & $2.35 \times 10^{23}$ & $5.83 \times 10^{25}$ & $2.64 \times 10^{25}$ & $3.19 \times 10^{25}$ & $4.00-4.25$ \\
\hline
\end{tabular}

GSC,R

0.7

0.5

GSC,Z
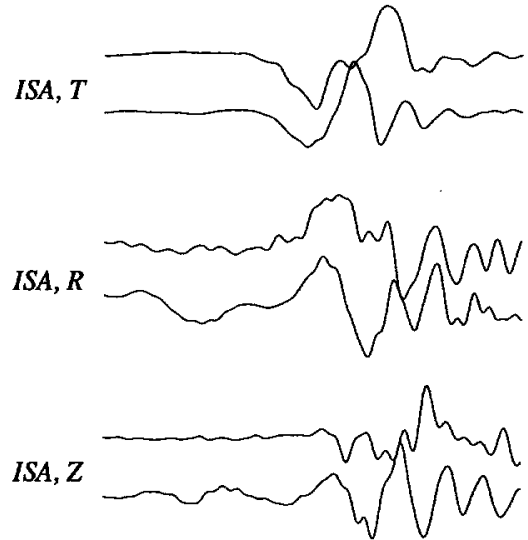

0.2

0.1

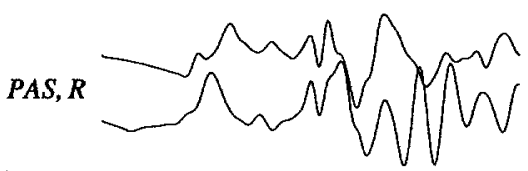

0.5

0.7
PAS, Z

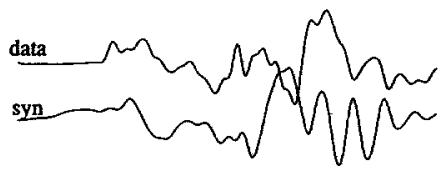

PFO, T

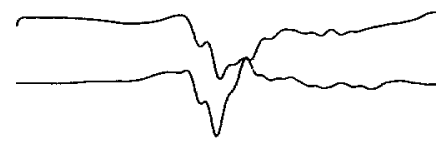

3.2

1.3

PFO, R

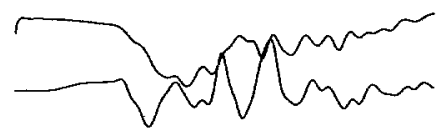

$P F O, Z$

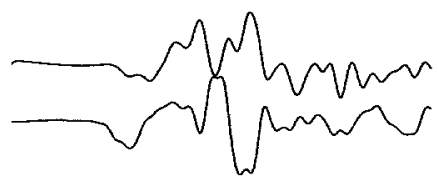

0.5

$S V D, T$

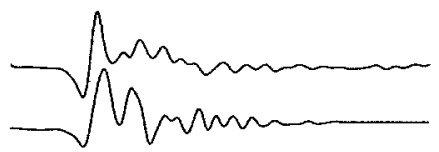

$S V D, R$

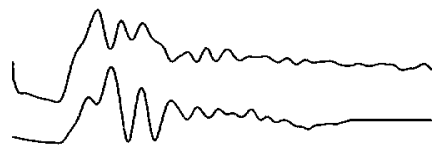

17:48 GMT aftershock as eGf

1-Fault Model NE, Bilateral

25 seconds

Figure 7. Line-source fault inversion results, in displacement, for a single-fault model striking $50^{\circ}$ (northeast). The 28 June 1992 17:48 GMT aftershock was selected as eGf. Synthetics are shown plotted below the data for each station, and relative amplitudes are indicated to the right of each pair of traces.

again based on aftershock distribution, as well as on the results from the empirical Green's function summation study. Due to directivity results and mainshock location (Figs. 3a and 3b), initial unilateral rupture was specified to occur on the NW-striking fault. Parameterization of the second fault is similar to that of the first: $161-\mathrm{km}$ blocks, with a point source in the middle of each. Given the relative amplitudes at stations GSC, ISA, and PAS, (i.e., GSC not substantially larger than PAS and smaller than ISA), and given the results for NE-trending faults in the single-fault study, unilateral and bilateral ruptures at a rupture velocity of $V_{r}$ $=2.7 \mathrm{~km} / \mathrm{sec}$ were initially assumed. Rupture velocities of
$1.7,2.3,3.0,3.3$, and $3.7 \mathrm{~km} / \mathrm{sec}$ were again tested, but the best results were obtained assuming $V_{r}=2.7$. We also test several other double-fault models (Figs. 8a and 8b). Lowest misfit is obtained from the NW-striking fault paired either with the unilaterally or bilaterally rupturing NE-striking fault, depending on the choice of eGf. A two-fault model composed of two NE-trending faults also provided low misfit values for both eGfs, though the synthetics failed to fit several key waveforms, including all three components of displacement recorded at station ISA. Since no choice of empirical Green's function is perfect, we present results from two eGfs and illustrate the consistencies between them. 

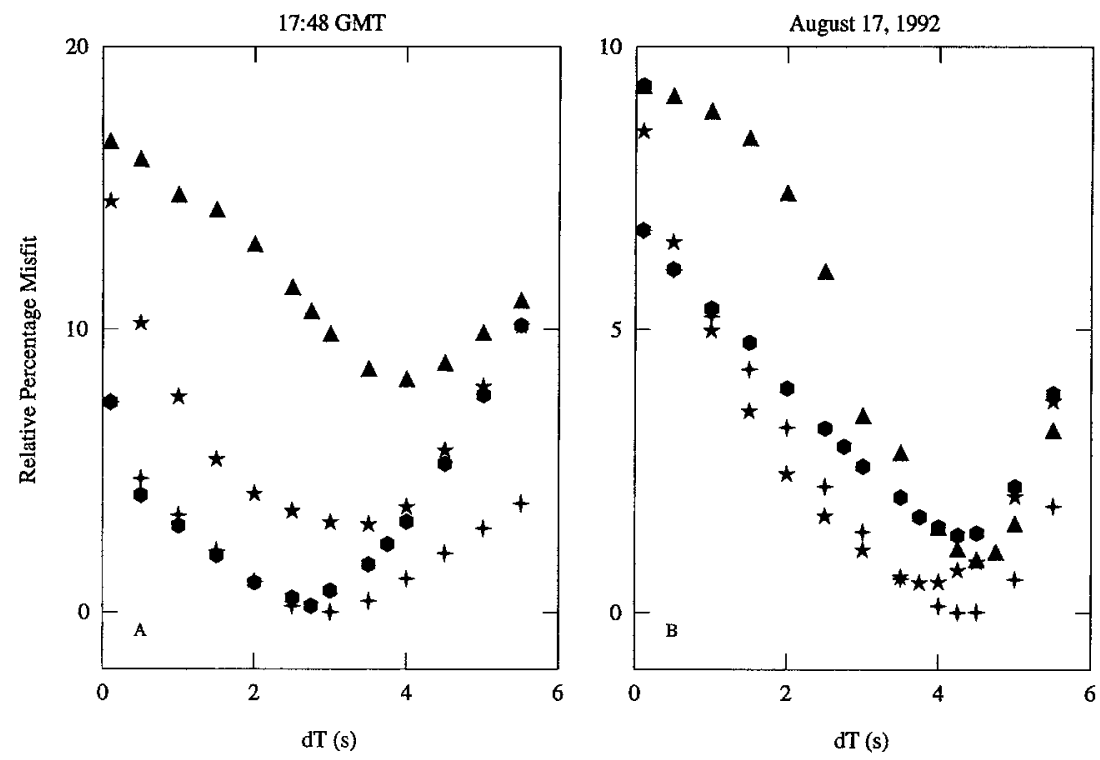

Figure 8. (a) Percentage misfit relative to the lowest misfit value for each eGf, plotted against delay time (in seconds) between the two ruptures for four two-fault models, from line-source modeling using the 28 June 1992 17:48 GMT aftershock as eGf. Values shown are percentage increase in misfit relative to the minimum misfit for all models. Each misfit value is normalized with respect to number of traces used in the inversion (in this case, 12). This is to facilitate comparisons between results for the two eGfs. Associated one-fault models are shown at delay time (dT) equals zero. For the one-fault models, a triangle indicates misfit value from a single NW-trending unilaterally rupturing fault, an octagon shows misfit from a single NE-striking unilaterally rupturing fault, and a star indicates that from a single bilaterally rupturing NE-striking fault. For the two-fault models, triangles indicate misfit results from a two-fault model composed of two unilaterally rupturing NW-striking faults; hexagons show results from two unilaterally rupturing NE-striking faults. Crosses show results from a NW-striking unilaterally rupturing fault, followed by a NE-striking unilaterally rupturing fault. Stars indicate misfit results from a NW-striking unilaterally rupturing fault, followed by a NE-striking bilaterally rupturing fault. (b) Norm of misfit plotted against delay time between the two ruptures for four two-fault models, from line-source modeling using the 17 August 1992 aftershock as eGf. Values shown are percentage increase in misfit relative to the minimum misfit for all models, and misfits are normalized with respect to the number of mainshock waveforms used in the inversion, in this case, 10. Misfit results from single-fault and double-fault models are indicated as in part (a).

We obtain a good fit to the data using the 28 June 1992 17:48 aftershock as an eGf and assuming an initial northwest-trending rupture, with the two-fault geometry described above (Fig. 9). Although depth mismatch between eGf and that observed has contributed to overlarge synthetic surface wave to $P_{\mathrm{nI}}$ wave amplitude ratios at some stations, we have matched the more unusual and salient characteristics of these waveforms. A comparison of least-squares misfit for the chosen single-fault model (NE-striking, bilateral rupture) and the two-fault model indicate a $11 \%$ improvement in overall weighted misfit for the two-fault model over the onefault model. Comparing the quantitative misfit values for each trace, we find some cases in which results for a twofault model are actually higher than those provided by the lowest error one-fault model, although the overall weighted misfit to the collective data set is decreased. Variance is decreased by approximately 11 to $49 \%$ for traces weighted most heavily in the inversion (ISA tangential 49\%; SVD radial 30\%, tangential 23\%; PFO tangential 11\%).

The distribution of subfault weights resulting from this inversion are shown in Figure 10. Here, we see the suggestion of two subevents on the NW-striking fault and moment release distributed in both directions on the NE-striking fault. The total moment for this inversion is $5.86 \times 10^{25}$ dyn-cm, which is equivalent to a moment magnitude of 6.44 , with $2.61 \times 10^{25}$ dyne-cm ( $44.6 \%$ of moment release) distributed on the NW-striking fault and $3.25 \times 10^{25}$ dyne-cm (55.4\% of moment release) distributed on the NE-striking fault. The best-fit time lag between rupture on the first and second faults is (Fig. 8a) $T_{\text {lag }}=3.75$ to $4.0 \mathrm{sec}$.

We also perform a line-source inversion for subfault weightings using the 17 August 1992 aftershock as eGf. This event has a source depth of about $15 \mathrm{~km}$ and produced highquality records at stations GSC, ISA, PAS, and PFO. In this 

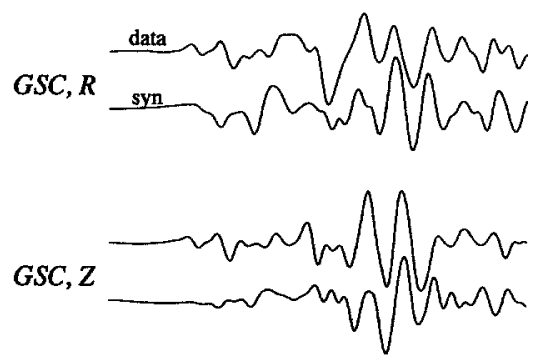

0.5

1.0

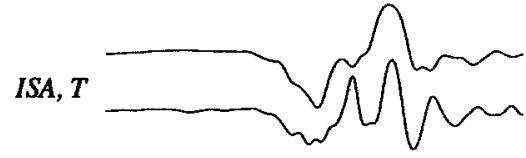

1.5

1.2

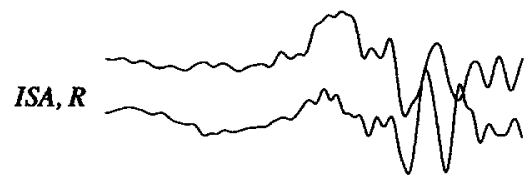

0.1

0.2

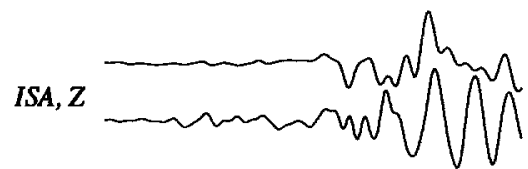

0.2

0.1

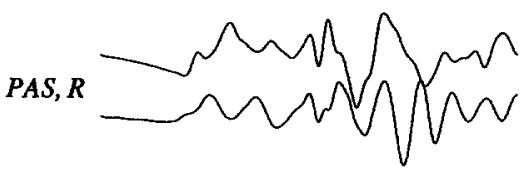

$P A S, Z$

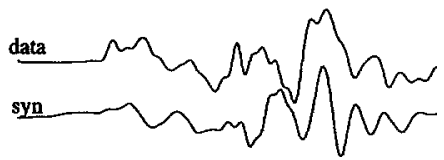

PFO, T

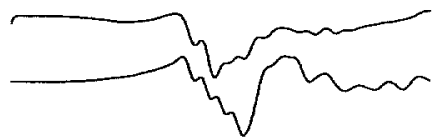

3.2

PFO, R

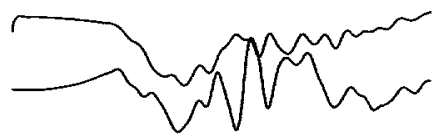

1.3

PFO, Z

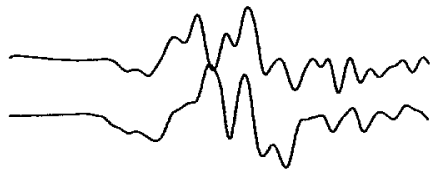

$S V D, T$

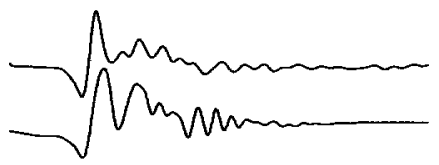

$S V D, R$

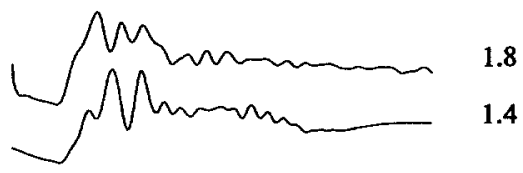

17:48 GMT aftershock as eGf

2-Fault Model

25 seconds

Figure 9. Line-source fault results, in displacement, for the choice of the 28 June 1992 17:48 GMT aftershock as eGf and assuming the fault orientation shown in Figure 11. Synthetics are shown plotted below the data for each station, and relative amplitudes are indicated to the right of each pair of traces. The rupture velocity was $V_{r}=2.7 \mathrm{~km} /$ sec for both faults, and best-fit time lag between rupture on the first (NW) and second (NE) faults (Fig. 8a) is $T_{\text {lag }}=3.75$ to $4.0 \mathrm{sec}$.

case, station SVD is not included in the inversion, as records were not available for this event. Results for the inversion using this eGf are shown in Figure 11, and distribution of subfault weights for this inversion is shown in Figure 12. The inversion featuring bilateral rupture on the second, NEstriking fault had lowest error, so we show these results here. Again, the inversion suggests two subevents on the NW trending fault, with moment release in both directions on the NE-SW trending fault. Total moment for this inversion is $5.83 \times 10^{25}$ dyn-cm, which is equivalent, to a moment magnitude of 6.44 , with $2.64 \times 10^{25}$ dyn-cm ( $45 \%$ of moment release) distributed on the $\mathrm{NW}$-trending fault and $3.19 \times$ $10^{25}$ dyn-cm (55\% of moment release) distributed on the NEtrending fault. The best-fit time lag between rupture on the first and second faults (Fig. 8b) is $T_{\text {lag }}=4.0$ to $4.25 \mathrm{sec}$.

The two line-source inversions thus yield consistent results, with a time lag of roughly $4 \mathrm{sec}$ between the onset of initial unilateral rupture on the NW plane and a second unilateral or bilateral subevent on the NE plane. The inferred moment partitioning between the NW- and NE-striking faults is roughly equal. These results are generally consistent with the eGf point-source results, which yielded a second subevent initiating a few kilometers S-SE of the first one. The inferred time lag between subevents is consistent with our optimal results from the point source eGf analysis (3.7 $\mathrm{sec}$ versus 3.75 to $4.25 \mathrm{sec}$ ). The line-source results are also consistent with results from the directivity analysis; the overall event directivity is controlled by the unilateral NW rupture rather than the NE-SW rupture, which may have been bilateral.

\section{Discussion}

The Big Bear mainshock was a significant, if enigmatic, earthquake in its own right. A $M_{b} 4.1$ foreshock that preceded the mainshock by only $40 \mathrm{sec}$, the lack of surface rupture, and the demonstrated source complexity all conspire to obscure the rupture history of this event. It is possible that 


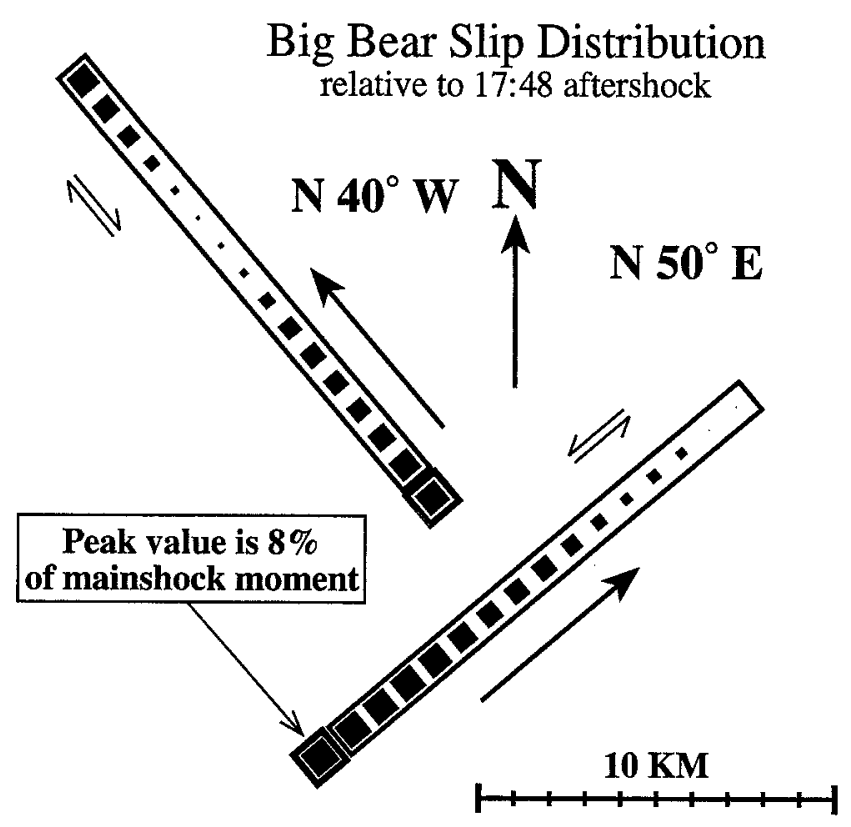

Figure 10. Cartoon showing the assumed twofault geometry for the 28 June 1992 17:48 GMT aftershock inversion and final distribution of subfault weightings obtained from this inversion. Note the two subevents on the NW-trending fault plane. Each subfault is a $1 \mathrm{~km}$ by $1 \mathrm{~km}$ square.

the two mainshock subevents occurred at different depths and thus that the mainshock "hypocentral depth" may never be accurately determined. These uncertainties inevitably complicate any analysis, including the eGf procedure presented in this article.

Notwithstanding these limitations, we have presented a combination of point-source eGf, line-source eGf, and directivity analysis that reaches a consistent rupture scenario for the Big Bear earthquake. Our interpretation derives some support from general geologic evidence that the NW-trending lineaments in the region are better developed than the NE-trending features (P. M. Sadler, personal comm., 1993) and from an independent engineering assessment that the damage pattern from the earthquake is suggestive of NWdirectivity (S. Mendes, personal comm., 1994).

We suggest the following scenario for the sequence: the 14:43 M 5.2 foreshock occurred near $34^{\circ} 10^{\prime} \mathrm{N}, 116^{\circ} 49^{\prime} \mathrm{W}$ and ruptured north-northeastward. A smaller, $M 4.0$ foreshock occurred in a similar location at 15:04 GMT. Rupture during the Big Bear earthquake began at 15:05 GMT at $34^{\circ}$ $12.4^{\prime} \mathrm{N}, 116^{\circ} 50.1^{\prime} \mathrm{W}$, to the north of the foreshocks, and ruptured primarily to the northwest, with possibly a few kilometers of rupture to the southeast as well. Approximately $4 \mathrm{sec}$ later, rupture initiated along a NE-striking surface close to the location of the foreshocks. Rupture along the NEstriking plane may have been bilateral.

Rupture on conjugate nodal planes, while considered unusual, has been suggested or inferred in other sequences, including the 1947 Manix earthquake (Doser, 1990), the
1984 Round Valley sequence (Priestly et al., 1988), the 1986 Chalfant sequence (Smith and Priestly, 1988), and the 1987 Superstition Hills sequence (Hudnut et al., 1989). In the 1984 Round Valley sequence, initial rupture on a NE-striking fault was followed within a few hours by activity on a NW-striking conjugate fault. The 1986 Chalfant sequence featured a $M_{l} 5.7$ foreshock that ruptured downward and to the southwest along a NE-striking fault, followed by a $M_{l}$ 6.4 mainshock that initiated deeper and ruptured upward along the NW-striking conjugate fault. In the Superstition Hills sequence, Hudnut et al. (1989) conclude that crossfault triggering occurred after a delay of about $11 \mathrm{hr}$. Coseismic rupture on conjugate normal faults was observed in the 1980 Irpinia, Southern Italy, sequence (Crosson et al., 1986; Bernard and Zollo, 1989), and conjugate normal faulting was observed in the 1984 Devil Canyon, Idaho, sequence (Jackson, 1994).

Classic cross-fault triggering features an L-shaped rupture on conjugate planes, consistent with predicted Coulomb stress change triggering (e.g., Hudnut et al., 1989). In our case, simple static stress considerations predict that unilateral NW rupture would trigger SW but not NE rupture on the conjugate surface. However, earthquake-triggering processes are likely to be more complex than simple Coulomb stress changes would dictate. Dynamic forces on the SW$\mathrm{NE}$ nodal plane may have been sufficient to overcome the Coulomb stress increase due to the NW rupture. It is moreover likely that, overall, the sequence of Big Bear subevents occurred in response to considerable static changes caused by the $M_{w}=7.3$ Landers event just $3 \mathrm{hr}$ earlier.

In addition to static stress changes caused by the Landers earthquake, it is possible that the Big Bear sequence accommodated rotational forces. The primary manifestation of clockwise rotation caused by the right lateral Landers rupture should be left lateral motion on NE-striking faults. However, the predominance of NW-striking lineaments within the San Bernardino mountains block suggests that the region may be subdivided into smaller blocks that do not each span the full width of the mountains. If this is the case, right lateral motion may occur on NW-striking faults within the San Bernardino mountains (i.e., right lateral shear is accommodated across a system of faults, rather than only on the bounding faults). The paucity of well-developed NE-trending faults and lineaments through the Big Bear region (P. M. Sadler, personal comm., 1993) supports this hypothesis.

The high relative amplitudes at station ISA northwest of the mainshock and on azimuth with the northwest-striking nodal plane provide prima facie evidence for substantial moment release along this surface. We note that these amplitudes cannot be explained as an artifact of bilateral rupture along the NE-striking plane because PFO would then be expected to have similar high amplitudes, which is not observed. However, it is possible that bilateral rupture of the second subsevent results in minimal northeast directivity.

We conclude that the previous presumption of a NEstriking mainshock rupture plane is attributed to an overall 

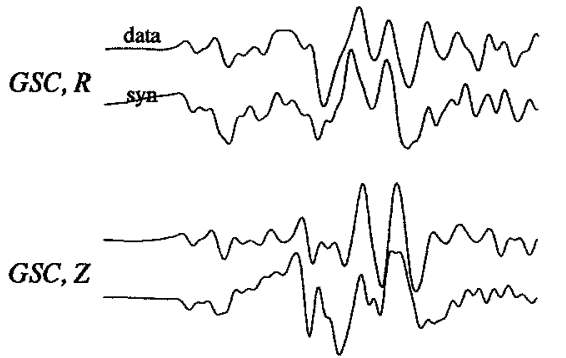

0.5

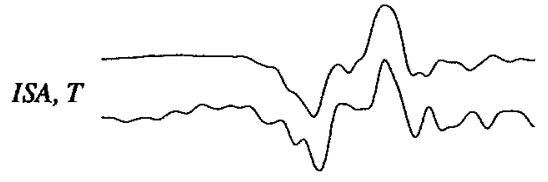

1.5

0.7

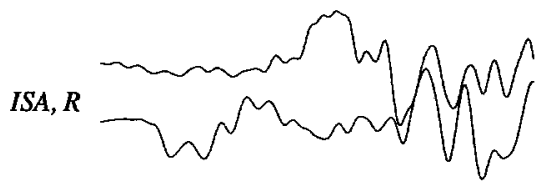

0.1

0.2

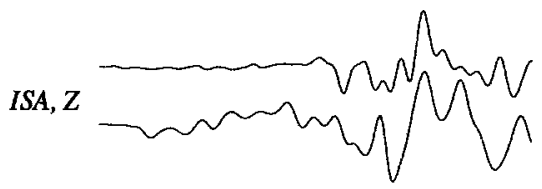

0.2

0.3

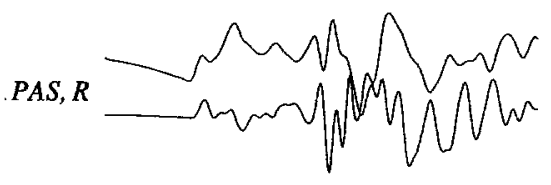

PAS, Z

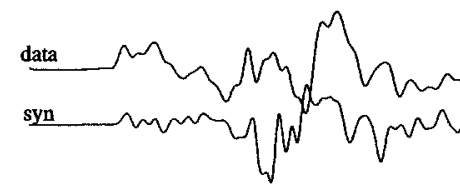

0.3

0.4

PFO, $T$

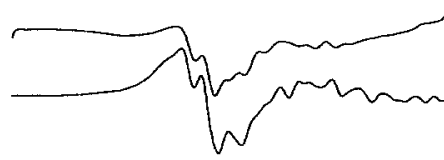

3.2

0.4

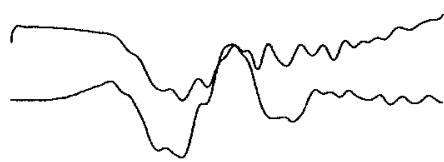

1.3

$P F O, Z$

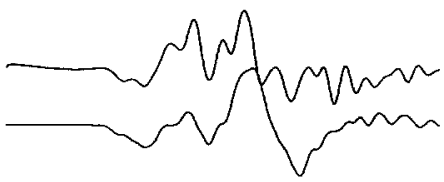

0.5

0.6
August 17, 1992 aftershock as eGf

2-Fault Model

\section{5 seconds}

Figure 11. Line-source fault results, in displacement, for the choice of the $17 \mathrm{Au}$ gust 1992 aftershock and assuming the fault orientation shown in Figure 12. The rupture velocity was $V_{r}=2.7 \mathrm{~km} / \mathrm{sec}$ for both faults, and best-fit time lag between rupture on the first (NW) and second (NE) faults (Fig. 8b) is $T_{\text {lag }}=4.0$ to $4.25 \mathrm{sec}$.

(long-term) aftershock distribution that is misleading. It is not necessarily true that regions of high mainshock slip will correspond to regions of the most intense aftershock activity; in fact, areas of high slip and/or total stress release may correlate instead with sparse aftershock activity (Beroza, 1991). We also note that a dense concentration of aftershocks occurred south of the Pinto Mountain fault (Fig. 1) within the Landers sequence, associated with only 20 to 40 $\mathrm{cm}$ of aftershock-related slip (Hough et al., 1993).

In the aftermath of the Landers mainshock, the Barstow region has also been characterized by high aftershock activity, in this case with no primary rupture. It is interesting to note that Barstow, the Pinto Mountain fault, and the proposed NE-trending Big Bear "fault" are all areas of high postseismic deformation (Shen et al., 1993). Moreover, several lines of evidence suggest that the Big Bear event was, overall, a high-stress-drop earthquake (Jones and Helmberger, 1993), and the NW-striking rupture could be shorter than the NE-striking rupture if the former were particularly high-stress drop.

Although surface rupture was not identified in the im- mediate aftermath of the Big Bear mainshock, possible evidence of surface rupture was observed, with a maximum of 3 to $4 \mathrm{~cm}$ of right lateral displacement over several hundred meters (Rasmussen, personal comm., 1993). The strike of this trace, which was roughly $\mathrm{N} 48^{\circ} \mathrm{W}$, agrees with our inferred rupture direction, displaced approximately $4 \mathrm{~km}$ to the southwest. Alternatively, these features have been interpreted as local slumping effects (K. Sieh, personal comm.).

Our results have several implications for the tectonic structure of the Big Bear region. The NW-trending rupture plane coincides with a topographic lineament that extends from the Sugarloaf epicenter past Moon Ridge (and the nearby subdivision of Moonridge), suggesting that this lineament is fault-controlled (L. Seeber, personal comm., 1993). Both the surface rupture and the NW-striking "Moon Ridge lineament" or fault are parallel to both the Helendale fault to the NE and to the distributed faults in the Mojave shear zone (Dokka et al., 1992), suggesting that the fabric of the Mojave shear zone may persist under the San Bernardino mountains.

Geological investigations in the San Bernardino moun- 


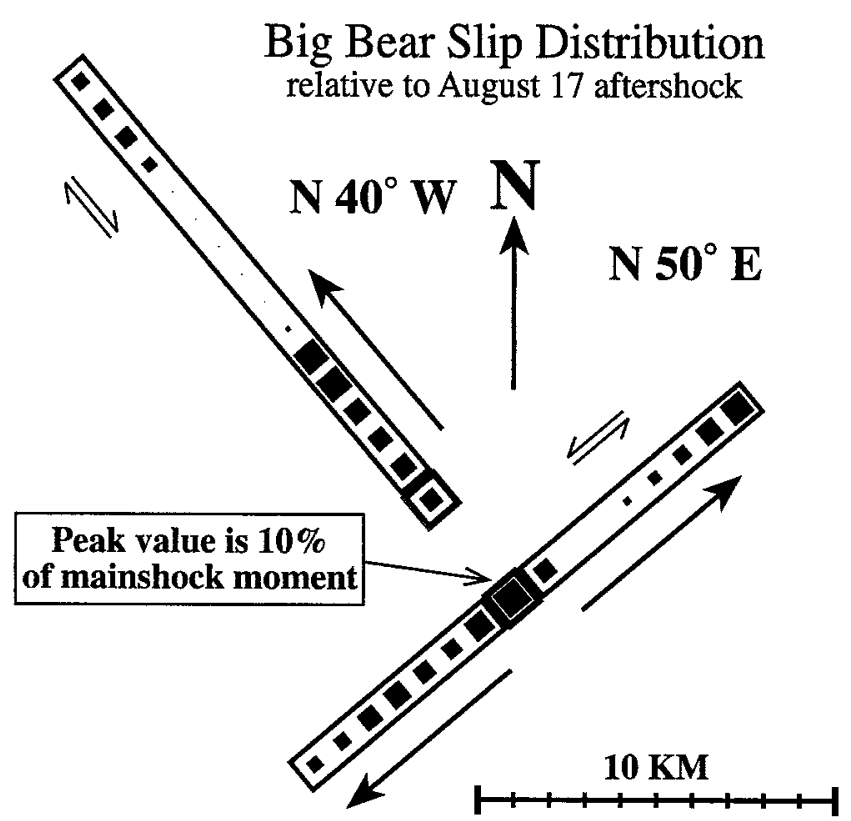

Figure 12. Cartoon showing the assumed twofault geometry for the inversion using the 17 August 1992 aftershock as eGf and final distribution of subfault weightings obtained from the inversion. Note the two subevents on the NW-trending fault plane. tains also provide evidence for both NE and NW faulting, with a better-developed NW-trending fabric (Sadler, 1993; Sadler, personal comm., 1993). The complex nature of the Big Bear rupture, the observed complications of aftershock mechanisms, and the distributed locations of the aftershocks further suggest that the San Bernardino mountains may be characterized by pervasive conjugate (NE/NW) fault sets. Thus, it is possible that numerous faults within the region are capable of producing earthquakes of moderate size.

The second implication of our results concerns the effect of the Landers/Big Bear sequence on the nearby San Andreas fault. Several studies (e.g., Stein et al., 1993; Harris and Simpson, 1993; Jaume and Sykes, 1992) have concluded that the stress changes caused by the Landers earthquake and the presumed (i.e., northeast-trending) Big Bear rupture would tend to move the San Andreas fault closer to failure both along a southern segment (Indio to the Salton Sea) and along the San Bernardino segment, while reducing normal stress on the San Andreas between the two segments. However, the NW-striking "Big Bear" fault is roughly parallel to the San Bernardino segment of the San Andreas and would thus tend to reduce its shear stress. Although a definitive partitioning of moment release on the two faults is beyond the scope of our investigations (and may be beyond the resolving capacity of the data), our results suggest that substantial moment release did occur on the presumed antithetic fault plane and that the effects of this event on the nearby San Andreas fault should be reexamined.

\section{Acknowledgments}

We thank Lisa Wald for providing us the SCSN location of the Big Bear event, Egill Hauksson for providing aftershock relocations, and Gary Rasmussen for bringing the Sugarloaf rupture to our attention. We thank Dave Wald for his invaluable help with the line-source inversion software, Leonardo Seeber and John Armbruster for their discussions, Suzanne Jackson for helpful suggestions, and Chuck Ammon for thorough and thoughtful reviews. This work was supported by contribution Number 5316, Division of Geological and Planetary Sciences, California Institute of Technology.

\section{References}

Aki, K. and P. Richards (1980). Quantitative Seismology, Theory and Methods, Vol. 2, W. H. Freeman and Company, New York, 807-812.

Ammon, C. J., A. A. Velasco, and T. Lay (1993). Rapid estimation of rupture directivity: Application to the 1992 Landers $\left(M_{s}=7.4\right)$ and Cape Mendocino $\left(M_{s}=7.2\right)$, California earthquakes, Geophys. Res. Lett. 20, 97-100.

Bakun, W. H. and C. G. Bufe (1975). Shear wave attenuation along the San Andreas fault zone in central California, Bull. Seism. Soc. Am. 65, 439-459.

Bernard, P. and A. Zollo (1994). The Irpinia (Italy) 1980 Earthquake: Detailed analysis of a complex normal faulting, J. Geophys. Res. 94, 1631-1647.

Beroza, G. C. and P. Spudich (1988). Linearized inversion for fault rupture behavior: application to the 1984 Morgan Hill, California earthquake, J. Geophys. Res. 93, 6275-6296.

Crosson, R. S., M. Martini, R. Scarpa, and S. C. Key (1986). The southern Italy earthquake of 23 November 1980: An unusual pattern of faulting, Bull. Seism. Soc. Am. 76, 381-394.

Dokka, R. K., D. F. MacConnell, and J. P. Ford (1992). Active and inactive faults of the northern Mojave Desert Block: Implications for strain partitioning in the Eastern California Shear Zone (abstract), EOS 73, 363.

Doser, D. I. (1990). A re-examination of the 1947 Manix, California, earthquake sequence and comparison to other sequences within the Mojave Block, Bull. Seism. Soc. Am. 80, 267-277.

Hadley, D. and H. Kanamori (1977). Seismic Structure of the Transverse Ranges, California, Geol. Soc. Am. Bull. 88, 1469-1478.

Harris, R. A. and R. W. Simpson (1992). Changes in static stress on southern California faults after the 1992 Landers earthquake, Nature $\mathbf{3 6 0}$, 251-254.

Hauksson, E., L. M. Jones, K. Hutton, and D. Eberhart-Phillips (1993). The 1992 Landers Earthquake Sequence: Seismological Observations, $J$. Geophys. Res. 98, 19835-19858.

Helmberger, D. V., R. Stead, P. Ho-Liu, and D. Dreger (1992). Broadband modeling of regional seismograms, Imperial Valley to Pasadena, Geophys. J. Int. 110, 42-54.

Hough, S. E., J. Mori, E. Sembera, G. Glassmoyer, C. Mueller, and S. Lydeen (1993). Southern surface rupture associated with the 1992 M7.4 Landers earthquake: Did it all happen during the mainshock? Geophys. Res. Lett. 20, 2615-2618.

Hudnut, K., L. Seeber, T. Rockwell, J. Gormacher, R. Klinger, S. Lindvall, and R. McElwain (1989). Surface ruptures on cross-faults in the 24 November 1987, Superstition Hills, California, earthquake sequence, Bull. Seism. Soc. Am. 79, 282-296.

Jackson, S. M. (1994), Seismic evidence of conjugate normal faulting: the 1984 Devil Canyon earthquake sequence near Challis, Idaho, Masters Thesis, Boise State University, Boise, Idaho.

Jaume, S. C. and L. R. Sykes (1992). Changes in State of Stress on Southern San Andreas Fault Resulting from the California Earthquake Sequence of April to June, 1992, Science 258, 1325-1329.

Jones, L. E. and D. V. Helmberger (1992). Broadband modeling of aftershocks from the Landers, Big Bear and Joshua Tree events (abstract), $\operatorname{EOS~73,383.~}$ 
Jones, L. E., D. V. Helmberger, and S. H. Hough (1993). Rupture Process of the June 28, 1992 Big Bear Earthquake, Geophys. Res. Lett. 20, $1907-1910$.

Kanamori, H., H-K. Thio, D. Dreger, E. Hauksson, and T. Heaton (1992). Initial Investigation of the Landers, California, earthquake of 28 June 1992 using TERRAscope, Geophys. Res. Lett. 19, 2267-2270.

Lawson, C. L. and R. J. Hanson (1974). Solving Least Squares Problems, Prentice-Hall, Inc., Englewood Cliffs, 340 pp.

Matti, J. C., D. M. Morton, and B. F. Cox (1992). The San Andreas Fault System in the vicinity of the central Transverse Ranges Province, Southern California, in Earthquake Geology: San Andreas Fault System Palm Springs to Palmdale, 35th Annual Meeting, Oct. 2-9, 1992, Association of Engineering Geologists, Los Angeles, 13-62.

Meisling, K. E. and R. J. Weldon (1989). Late Cenozoic tectonics of the northwestern San Bernardino Mountains, southern California, Bull. Geol. Soc. Am. 101, 106-128.

Mori, J. and S. Hartzell (1990). Source inversion of the 1988 Upland, California earthquake: determination of fault plane for a small event, Bull. Seism. Soc. Am. 80, 507-518.

Mueller, C. S. (1985). Source pulse enhancement by deconvolution of an empirical Green's function, Geophys. Res. Lett. 12, 33-36.

Priestly, K. F., K. D. Smith, and R. S. Cockerham (1988). The 1984 Round Valley, California earthquake sequence, Geophys. J. 95, 215-225.

Sadler, P. M. (1993). The Santa Ana basin of the central San Bernardino Mountains: Evidence of the timing of uplift and strike slip relative to the San Gabriel Mountains, GSA Memoir 178, 307-321.

Sieh, K., L. Jones, E. Hauksson, K. Hudnut, D. Eberhart-Phillips, T. Heaton, S. Hough, K. Hutton, H. Kanamori, A. Lilje, S. Lindvall, S.
McGill, J. Mori, C. Rubin, J. Spotilia, J. Stock, H. K. Thio, J. Treimon, B. Wernicke, and J. Zachariasen (1993). Near-field investigations of the Landers earthquake sequence, April to July, 1992, Science 260, 171-176.

Shen, Z-K, D. D. Jackson, Y-J Feng, M. Cline, and M. Kim (1993). Postseismic Deformation following the Landers Earthquake, California, June 28, 1992, Bull. Seism. Soc. Am. 84, 780-791.

Smith, K. D. and K. F. Priestly (1988). The foreshock sequence of the 1986 Chalfant, California earthquake, Bull. Seism. Soc. Am. 78, 172-187.

Stein, R. S., G. C. P. King, and J. Lin (1992). Change in failure stress on the Southern San Andreas fault system caused by the 1992 Magnitude $=7.4$ Landers earthquake, Science 258, 1328-1332.

Wennerberg, L. (1990). Stochastic summation of empirical Green's functions, Bull. Seism. Soc. Am. 80, 1418-1432.

Zhao L-S. and D. V. Helmberger (1994). Source Estimation from Broadband Regional Seismograms, Bull. Seism. Soc. Am. 84, 91-104.

Seismological Laboratory

California Institute of Technology

Pasadena, California 91125

(L.E.J.)

U.S. Geological Survey

Pasadena, California 91006

(S.E.H.)

Manuscript received 12 August 1993. 